Note

\title{
Malonaldehyde Content in Some Breads and Its Change during Storage
}

(Received November 15, 2004)

\author{
Tadashi SakaI ${ }^{*}{ }^{\dagger}$ and Satoshi Kawahara* \\ (*Department of Biochemistry and Applied Biosciences, Faculty of Agriculture, \\ University of Miyazaki: Miyazaki-shi, Miyazaki 889-2192, Japan; ${ }^{\dagger}$ Corresponding author)
}

\begin{abstract}
Malonaldehyde (MA) content in plain bread, French bread, and croissants was analyzed. MA was detected in all the analyzed samples. The MA and lipid contents in croissants were higher than those in other breads. Changes in MA content in plain bread, French bread, and croissants stored at $4^{\circ} \mathrm{C}$ were examined after 0,2 , and 4 days of storage. The MA content in all the bread samples increased during the storage period. The highest increase of MA content was observed in French bread.
\end{abstract}

Key words: malonaldehyde; lipid peroxidation; bread; fatty acid

\section{Introduction}

Bakery products, particularly those with a high lipid content, tend to become rancid after prolonged storage $^{1,2)}$, owing to the peroxidation of polyunsaturated fatty acids. During lipid peroxidation, polyunsaturated fatty acids yield malonaldehyde (MA), which is directly or indirectly involved in the multistage process of carcinogenesis, particularly DNA damage, sometimes leading to mutations in tumorsuppressor genes ${ }^{3)}$. In addition, when MA coexists with nitrous acid and secondary amines ${ }^{4)}$, it accelerates the formation of carcinogenic nitrosamine ${ }^{2}$.

Numerous papers have reported lipid oxidation in various food items ${ }^{5)}$, 6); however, to our knowledge, only a few papers deal with lipid oxidation in breads ${ }^{7), 8)}$. From the viewpoint of food hygiene, it is important to analyze the MA content in breads. Therefore, MA content and its change were examined in several types of breads stored at $4^{\circ} \mathrm{C}$.

\section{Materials and Methods}

\section{Materials and storage experiments}

Plain breads, French breads and croissants kept at room temperature for 2-4 hours after baking were obtained from two bakeries (A and B). Crusts were removed from plain and French breads before analysis. Each bread was minced in a food processor for 1 min to prepare samples. MA contents in five samples of each bread were analyzed. In addition breads just out of the oven were obtained from bakery A. In order to avoid the effects of temperature fluctuation, each bread was wrapped with plastic wrapping paper followed by aluminum foil and stored at $4^{\circ} \mathrm{C}$. The MA contents of 3 samples from each bread were analyzed after 0,2 and 4 days of storage.

\section{$M A$ analysis}

The 1,3-diethyl-2-thiobarbituric acid (DETBA) assay is based on the method of Sakai et al. ${ }^{9)}$ One gram of each bread sample was homogenized with $9 \mathrm{~mL}$ of ice-cooled $10 \mathrm{mmol} / \mathrm{L}$ sodium phosphate buffer ( $\mathrm{pH}$ 7.0) in a Polytron homogenizer at $0^{\circ} \mathrm{C}$. An aliquot (less than $0.4 \mathrm{~mL}$ ) of the homogenate was transferred to a screw-capped tube containing $0.2 \mathrm{~mL}$ of $8 \% \mathrm{SDS}$ and $0.2 \mathrm{~mL}$ of 20 $\mathrm{mmol} / \mathrm{L}$ butyl hydroxy toluene in ethanol, and the final volume of mixture was made up to $0.8 \mathrm{~mL}$ with distilled water. After the addition of $3.2 \mathrm{~mL}$ of $12.5 \mathrm{mmol} / \mathrm{L}$ DETBA in $0.125 \mathrm{~mol} / \mathrm{L}$ sodium phosphate buffer $(\mathrm{pH}$ 3.0), the solution was mixed, heated in a water bath at $95^{\circ} \mathrm{C}$ for $15 \mathrm{~min}$, and quickly cooled under running tap water. To extract the DETBA-MA adduct, $4 \mathrm{~mL}$ of ethyl acetate was added, and the mixture was shaken vigorously. The ethyl acetate extract $(2.4 \mathrm{~mL})$ containing the DETBA-MA adduct was transferred to another tube and evaporated in vacuo. The residue was dissolved in $150 \mu \mathrm{L}$ of methanol, and $10 \mu \mathrm{L}$ of the sample was subjected to HPLC under the following conditions: column, Inertsil ODS (5 $\mu \mathrm{m}$ particle size, $250 \mathrm{~mm} \times 4.6$ mm i.d.; GL Sciences, Tokyo, Japan); mobile phase, acetonitrile- $0.1 \mathrm{~mol} / \mathrm{L}$ sodium chloride $(75: 25, \mathrm{v} / \mathrm{v})$; flow rate, $1.0 \mathrm{~mL} / \mathrm{min}$; detection, excitation at $515 \mathrm{~nm}$ and emission at $555 \mathrm{~nm}$.

\section{Total lipids and fatty acids analysis}

Total lipids were extracted from the breads by the method of Folch et ll $^{10)}$ and estimated by gravimetric analysis. The content of fatty acids was measured by gas chromatography using $n$-octadecane as internal standard according to Takenoyama et al. ${ }^{11)}$

\section{Statistical analysis}

All the data were analyzed by ANOVA and significant differences among means were determined by the Duncan multiple range tests ${ }^{12)}$. 
Table 1. MA Content $(\mu \mathrm{mol} / \mathrm{g})$ in Bread Samples

\begin{tabular}{cccc}
\hline \hline & Plain bread & French bread & Croissants \\
\hline Bakery A & $0.92 \pm 0.22$ & $0.65 \pm 0.02$ & $4.43 \pm 0.39$ \\
Bakery B & $0.86 \pm 0.18$ & $0.48 \pm 0.04$ & $4.36 \pm 0.22$ \\
\hline
\end{tabular}

Mean $(n=5) \pm$ standard deviation

\section{Results and Discussion}

Table 1 shows the MA content in plain bread, French bread, and croissants.

The MA content in each bread sample obtained from bakery A was higher than that from bakery B; though the difference was not significant. The MA content in croissants obtained from both bakeries was significantly higher than that in other breads. Table 2 shows the lipid contents of these breads.

The lipid content of croissants was much higher than those of other breads. The composition of 18:2 fatty acid was low in croissants, but high in other breads. High 18:2 fatty acid content may be associated with high MA content, because fatty acids containing more than 2 double bonds generate MA during lipid peroxidation ${ }^{3)}$.

Figure 1 shows the changes in MA content in plain bread, French bread, and croissants stored at $4^{\circ} \mathrm{C}$. The MA content in these breads increased during 4 days of storage at $4^{\circ} \mathrm{C}$, indicating that lipid peroxidation occurred during the storage period. Because the composition of $18: 2$ fatty acid is very high in French bread, the MA content of this bread may increase rapidly after 2 days of storage. After 4 days of storage, the MA content in croissants was $3.29 \pm 0.24 \mu \mathrm{mol} / \mathrm{g}$. The MA content in croissants shown in Table 1 were higher than that in the samples shown in Fig. 1, possibly because the former were kept at room temperature for 2-4 hours after baking. From the viewpoint of food hygiene, it is noteworthy that the MA content in croissants was extremely high and increased even when they were they were stored at $4^{\circ} \mathrm{C}$.

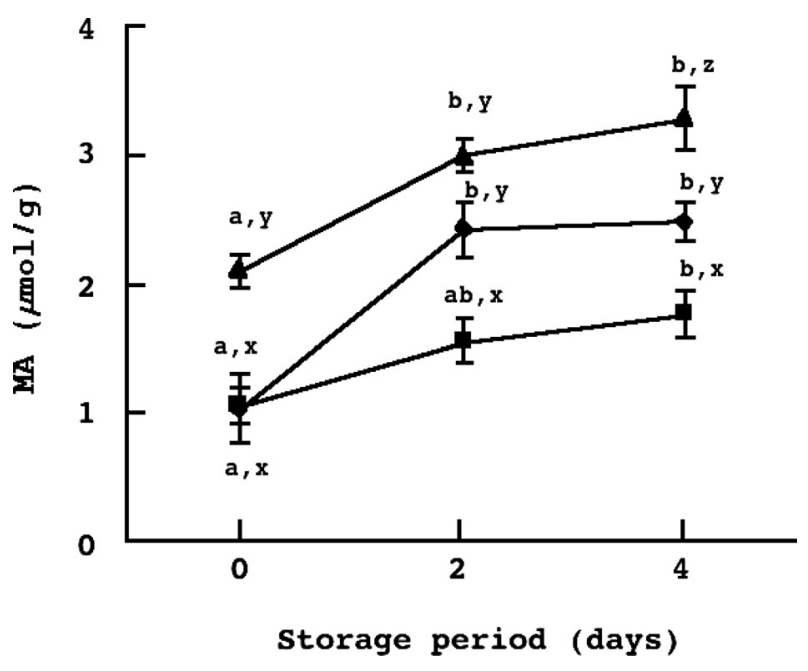

Fig. 1. Changes in MA content in breads stored at $4^{\circ} \mathrm{C}$ Error bars indicate the standard deviations of the mean of triplicate measurements. $\mathbf{\square}$ : Plain bread, ४: French bread, $\boldsymbol{\Delta}$ : Croissants. Script $a-b$ indicate the difference between storage period in the breads. Script $\mathrm{x}^{-} \mathrm{Z}$ indicate the difference between each bread. Different script indicate significantly different $(p<0.05)$.

As mentioned in the introduction, $\mathrm{MA}$ is a carcinogen $^{2,3)}$ and accelerates the formation of nitrosamine ${ }^{2)}$ in the presence of nitrous acid or secondary amines ${ }^{4}$. From the viewpoint of food hygiene, it is important to analyze the MA contents in many types of breads and to find way to suppress MA formation in them, because bread is one of the staple food items in Japan. Studies of the effect of some antioxidants on MA content in the breads are in progress in our laboratory.

\section{Acknowledgments}

We thank Ms. M. Asada and N. Miki (Faculty of Agriculture, University of Miyazaki) for their technical assistance.

Table 2. Total Lipid Contents (wt\%) and Fatty Acids Composition (\%) in Breads

\begin{tabular}{|c|c|c|c|c|c|c|}
\hline & Plain bread ${ }^{a}$ & Plain bread ${ }^{\mathrm{b}}$ & French bread ${ }^{a}$ & French bread ${ }^{b}$ & Croissant $^{\mathrm{a}}$ & Croissant $^{\mathrm{b}}$ \\
\hline Total lipid & 4.13 & 3.16 & 1.15 & 0.75 & 21.29 & 23.5 \\
\hline \multicolumn{7}{|l|}{ Fatty acid } \\
\hline $12: 0$ & 3.44 & 1.48 & 0.14 & 0.05 & 3.49 & 1.14 \\
\hline $14: 0$ & 2.61 & 3.52 & 0.28 & 0.16 & 9 & 4.74 \\
\hline $14: 1(n-5)$ & 0.05 & 0.22 & 0 & 0 & 1.67 & 0.97 \\
\hline $15: 0$ & 0.11 & 0.23 & 0.08 & 0 & 1.12 & 0.64 \\
\hline $16: 0$ & 17.13 & 23.08 & 16.83 & 19.75 & 29.52 & 30.83 \\
\hline $16: 1(\mathrm{n}-7)$ & 3.67 & 0.31 & 2.5 & 0.08 & 3.71 & 0.87 \\
\hline $17: 0$ & 0.37 & 0.22 & 0.09 & 0.09 & 0.9 & 0.39 \\
\hline $18: 0$ & 6.55 & 6.76 & 1.54 & 2.75 & 8.97 & 10.57 \\
\hline $18: 1(n-9)$ & 41.86 & 46.96 & 14.27 & 14.27 & 32.83 & 43.18 \\
\hline $18: 2(n-6)$ & 21.68 & 15.44 & 61.87 & 59.99 & 8.01 & 6.18 \\
\hline $18: 3(n-3)$ & 2.13 & 1.6 & 2.39 & 2.73 & 0.78 & 0.49 \\
\hline $20: 0$ & 0.39 & 0.19 & 0 & 0.14 & 0 & 0 \\
\hline
\end{tabular}

\footnotetext{
a Obtained from bakery A ${ }^{\mathrm{b}}$ Obtained from bakery B
} 


\section{References}

1) Smith, J. P., Daifas, D. P., El-Khoury, W., Koukoutsis, J., El-Khoury, A., Shelf life and safety concerns of bakery products-A review. Crit. Rev. Food Sci. Nutr., 44, 19-55 (2004).

2) Ray, G., Husain, S. A., Oxidants, antioxidants and carcinogenesis. Indian J. Exp. Biol., 40, 1,213-1,232 (2002).

3) Marnett, L. J., Lipid peroxidation-DNA damage by malonaldehyde. Mutat. Res., 424, 83-95 (1999).

4) Ohshima, T. "Shishitu (Lipid)" Abe, H., Fuke, S. eds., Tokyo, Asakura Publishing, 1994, p. 21-31. (ISBN 4-25443036-1)

5) Shamberger, R. J., Shamberger, B. A., Willis, C. E., Malonaldehyde content of food. J. Nutr., 107, 1,404-1,409 (1977).

6) Ladikos, D., Lougovios, V., Lipid oxidation in muscle foods: A review. Food Chem., 35, 295-314 (1990).

7) Yordanov, N. D., Mladenova, R., EPR study of free radicals in bread. Spectrochim. Acta, Part A, 60, 1,395-1,400
(2004).

8) Lindenmeier, M., Hofmann, T., Influence of baking conditions and precursor supplementation on the amount of the antioxidant pronyl-1-lysine in bakery product. J. Agric. Food Chem., 52, 350-354 (2004).

9) Sakai, T., Habiro, A., Kawahara, S., High-performance liquid chromatographic analysis of 1,3-diethyl-2-thiobarbituric acid-malonaldehyde adduct in fish meat. J. Chromatogr. B, 726, 313-316 (1999).

10) Folch, J., Lefes, M., Sloane Stanley, G. H., A simple method for the isolations and purification of total lipids from animal tissues. J. Biol. Chem., 226, 497-509 (1957).

11) Takenoyama, S., Kawahara, S., Murata, H., Yamauchi, K., Investigation of some preparation procedures of fatty acid methyl esters for capillary gas-liquid chromatographic analysis of conjugated linoleic acid in meat. Animal Sci. J., 70, 336-342 (1999).

12) Duncan, D. B., Multiple range and multiple $F$ tests. Biometrics, 11, 1-42 (1955). 